\title{
Effect of genetic background and activating stimulus on the timing of meiotic cell cycle progression in parthenogenetically activated mouse oocytes
}

\author{
Elena Ibáñez ${ }^{1}$, David F Albertini ${ }^{2}$ and Eric W Overström ${ }^{1,2}$ \\ ${ }^{1}$ Department of Biomedical Sciences, Tufts University School of Veterinary Medicine, North Grafton, \\ Massachusetts 01536, USA and ${ }^{2}$ Department of Anatomy and Cellular Biology, Tufts University School of Medicine, \\ Boston, Massachusetts 02111, USA
}

Correspondence should be addressed to E W Overström who is now at Department of Biology and Biotechnology,

Worcester Polytechnic Institute, 100 Institute Road, Worcester, Massachusetts 01609-2280, USA; Email: ewo@wpi.edu

(E Ibáñez is now at Departament de Biologia Cellular, Fisiologia i Immunologia, Facultat de Ciències, Universitat Autònoma de Barcelona, 08193 Bellaterra, Spain)

(D F Albertini is now at Department of Molecular and Integrative Physiology, Kansas University Medical Center, Kansas City,

Kansas 66160-7401, USA)

\begin{abstract}
With the aim of investigating the effects of oocyte genotype and activating stimulus on the timing of nuclear events after activation, oocytes collected from hybrid B6D2F1, inbred C57BL/6 and outbred CF-1 and immunodeficient nude (NU/+) females were activated using ethanol or strontium and fixed at various time-points. Meiotic status, spindle rotation and second polar body (PB2) extrusion were monitored by fluorescence microscopy using DNA-, microtubule- and microfilament-selective probes. Although activation efficiency was similar in all groups of oocytes, a significant percentage of CF- 1 and NU/+ oocytes treated with ethanol and of $\mathrm{C} 57 \mathrm{BL} / 6$ oocytes treated either with ethanol or strontium failed to complete activation and became arrested at a new metaphase stage (MIII) after PB2 extrusion. C57BL/6 oocytes also showed slower release from MII arrest but faster progression to telophase (TII) after ethanol exposure, and they exhibited the most rapid exit from TII under both activation treatments. Strontium caused delayed meiotic resumption, spindle rotation and PB2 extrusion, but rapid TII exit, in B6D2F1, CF-1 and NU/+ oocytes when compared with ethanol. Compared with all other strains, NU/+ oocytes were significantly slower in completing spindle rotation and PB2 extrusion, irrespective of the activating stimulus, and a significant decrease in activation rates and pace of meiotic progression was observed after strontium exposure. Thus, our findings demonstrated that the kinetics of meiosis resumption and completion, spindle rotation and PB2 extrusion following parthenogenetic activation depends on both genotype-specific factors and on the activation treatment applied.
\end{abstract}

Reproduction (2005) 129 27-38

\section{Introduction}

In most mammalian species, ovulated oocytes are arrested at metaphase of the second meiotic division (MII). This arrest is characterized by a high maturation-promoting factor (MPF) activity (Nurse 1990), which is maintained by a cytostatic factor (CSF) (Masui 1991). Under natural conditions, exit from the MII arrest is accomplished by fertilization, which triggers a series of transient rises in intracellular $\mathrm{Ca}^{2+}$ concentration that last for several hours (Cuthbertson \& Cobbold 1985, Swann 1990). These calcium transients cause inactivation of CSF, possibly through activation of $\mathrm{Ca}^{2+}$-calmodulin-dependent protein kinase II (CaMKII), and subsequent inactivation of MPF (Collas et al. 1995, Zernicka-Goetz et al. 1995). Intracellular $\mathrm{Ca}^{2+}$ oscillations at fertilization also initiate a series of subcellular and biochemical changes in oocytes, including cortical granule exocytosis, modifications of zona pellucida glycoproteins, recruitment of maternal mRNAs, resumption of meiosis, second polar body (PB2) extrusion, pronuclear formation, DNA synthesis and first mitotic cleavage (Schultz \& Kopf 1995). Collectively, these events are referred to as oocyte activation. Meiotic resumption after activation is characterized by chromatid segregation and spindle elongation during the transition from MII to anaphase (AII) and telophase II (TII). At the same time, in mouse oocytes, the spindle rotates from a parallel to a perpendicular orientation relative to the plasma membrane, and the PB2 is extruded (Maro et al. 1984, Liu et al. 2000, Ibáñez et al. 2003). Finally, chromatin is decondensed, 
pronuclear envelopes form, spindle microtubules depolymerize and the interphase microtubular network is assembled. MPF inactivation is essential for meiotic resumption and progression to interphase, whereas the inactivation of MAP kinase (MAPK), a component of CSF, is associated with chromatin decondensation, pronuclear formation, initiation of DNA synthesis and changes in microtubule dynamics (Moos et al. 1995, Carroll et al. 2000).

Although sperm supply the natural stimulus responsible for oocyte activation, oocytes may also be activated parthenogenetically, without the contribution of sperm, by a variety of physical and chemical stimuli (reviewed by Macháty \& Prather 1998, Alberio et al. 2001). Most artificial stimuli activate oocytes by a mechanism similar to that used by the sperm, i.e. inducing an increase in the intracellular $\mathrm{Ca}^{2+}$ levels. In mouse oocytes, ethanol has been frequently employed as an activating agent (Cuthbertson et al. 1981, Cuthbertson 1983, Winston \& Maro 1995). Ethanol activates oocytes by promoting the formation of inositol 1,4,5-trisphosphate $\left(\mathrm{IP}_{3}\right)$ at the plasma membrane and the influx of extracellular $\mathrm{Ca}^{2+}$ (Ilyin \& Parker 1992), causing a large, single rise in intracellular $\mathrm{Ca}^{2+}$ concentration (Cuthbertson et al. 1981). Strontium is another popular activating agent, currently used in mouse nuclear transfer protocols (Wakayama et al. 1998). It induces repetitive $\mathrm{Ca}^{2+}$ transients, which last for several hours, probably by displacing bound $\mathrm{Ca}^{2+}$ in the oocyte, but also by inducing $\mathrm{Ca}^{2+}$ release from intracellular stores (Kline \& Kline 1992, Bos-Mikich et al. 1995).

Parthenogenetic activation can be used as a model to study biochemical and morphological changes occurring in the oocyte during fertilization and early embryonic development, and it is a critical component of the cloning procedure. Because of this, several studies have been performed to date on the activation of mouse oocytes using various artificial stimuli. The majority of these studies have focused on the comparison of activation rates, usually measured by the presence of a pronucleus several hours after activation, or on the comparison of parthenogenetic development up to the blastocyst stage, of oocytes from the same strain activated with different treatments (Cuthbertson 1983, O'Neill et al. 1991, Bos-Mikich et al. 1995, 1997, Kishikawa et al. 1999). According to these criteria, differences in oocyte activation efficiencies have been observed depending on the activating stimulus used. Nevertheless, only a few studies have been reported on the activation efficiencies induced by artificial stimuli on oocytes from different strains of mice, and the results of these studies indicate that parthenogenetic activation and development is clearly dependent upon oocyte genetic background (Marcus 1990, Rybouchkin et al. 1996, Gao et al. 2004).

In the present work, oocytes collected from several strains of mice were subjected to parthenogenetic activation, using either ethanol or strontium, with the aim of investigating whether oocyte genetic background and activating stimulus influence nuclear events following artificial activation. In particular, the effects of these two factors on the kinetics of meiotic cell cycle resumption and completion, spindle rotation and PB2 extrusion were evaluated. Mouse strains chosen as oocyte donors were B6D2F1, C57BL/6 and CF-1, as common representatives of hybrid, inbred and outbred strains respectively. Oocytes collected from immunodeficient heterozygous nude females (NU/+), of an outbred background, were also included in the study, as delayed PB2 extrusion after activation had been observed in these oocytes in previous studies by our group (E Ibáñez, DF Albertini and EW Overström, unpublished results).

\section{Materials and Methods \\ Collection of MII oocytes}

Hybrid B6D2F1 (C57BL/6 $\times \mathrm{DBA} / 2)$, inbred C57BL/6 and outbred CF-1 and immunodeficient nude (NU/+) female mice (Charles River Laboratories, Wilmington, MA, USA) were used as oocyte donors. Animal care and procedures were conducted according to protocols approved by the Tufts University Institutional Animal Care and Use Committee. Females (8-10 weeks old) were induced to superovulate by intraperitoneal injection of $5 \mathrm{IU}$ equine chorionic gonadotropin (eCG; Calbiochem, San Diego, CA, USA) followed $48 \mathrm{~h}$ later by $5 \mathrm{IU}$ human chorionic gonadotropin (hCG) (Calbiochem). In vivo ovulated MII oocytes were recovered from oviducts $16 \mathrm{~h}$ post-hCG injection in Hepes-buffered potassium simplex optimized medium (H-KSOM; Speciality Media, Phillipsburg, NJ, USA) and cumulus cells were dispersed by incubation in $150 \mathrm{U}$ bovine testicular hyaluronidase/ml (Sigma, St Louis, $\mathrm{MO}, \mathrm{USA}$ ) in $\mathrm{H}-\mathrm{KSOM}$ at $37^{\circ} \mathrm{C}$ for $5 \mathrm{~min}$. Cumulus-free oocytes were then washed three times in fresh H-KSOM and immediately activated.

\section{Oocyte activation and culture}

Oocytes were parthenogenetically activated using two different chemical treatments. For ethanol activation, oocytes were treated for $5 \mathrm{~min}$ at $37^{\circ} \mathrm{C}$ in $\mathrm{H}-\mathrm{KSOM}$ containing $7 \%(\mathrm{v} / \mathrm{v})$ ethanol. Oocytes were then washed twice in $\mathrm{H}-\mathrm{KSOM}$ and cultured for up to $6 \mathrm{~h}$ at $37^{\circ} \mathrm{C}$ under $5 \%$ $\mathrm{CO}_{2}$ in air in KSOM medium containing both non-essential and essential amino acids (Specialty Media) and supplemented with $1 \mathrm{mg}$ bovine serum albumin $(B S A) / \mathrm{ml}$. When strontium was used as the activating agent, oocytes were cultured for up to $6 \mathrm{~h}$ in $\mathrm{Ca}^{2+}$-free KSOM (Specialty Media) containing $10 \mathrm{mmol} \quad \mathrm{SrCl}_{2} / \mathrm{ml}$ (Sigma). Initial exposure of MII oocytes to either ethanol or strontium was considered as time zero post-activation (р.a.).

To monitor meiotic cell cycle resumption and progression after activation, ethanol- and strontium-treated oocytes were fixed at 5-min intervals, from $5 \mathrm{~min}$ to $20 \mathrm{~min}$ p.a., and then at 30-min intervals until $5 \mathrm{~h} 50 \mathrm{~min}$ p.a. 


\section{Fixation of oocytes and processing for} immunofluorescence analysis

At the defined time-points after activation, oocytes were fixed and extracted for $30 \mathrm{~min}$ at $37^{\circ} \mathrm{C}$ in a microtubule stabilizing buffer $(0.1 \mathrm{~mol}$ PIPES/ml, pH 6.9, $5 \mathrm{mmol}$ $\mathrm{MgCl}_{2} / \mathrm{ml}$ and $\left.2.5 \mathrm{mmol} \mathrm{EGTA} / \mathrm{ml}\right)$ containing $3.7 \%(\mathrm{v} / \mathrm{v})$ formaldehyde, $0.1 \%(\mathrm{v} / \mathrm{v})$ Triton X-100, $1 \mu \mathrm{mol}$ taxol $/ \mathrm{ml}$, $0.01 \%(\mathrm{w} / \mathrm{v}$ ) aprotinin, $1 \mathrm{mmol}$ dithiothreitol $/ \mathrm{ml}$ and $50 \%$ (v/v) deuterium oxide (Messinger \& Albertini 1991). Fixed oocytes were stored until processing at $4{ }^{\circ} \mathrm{C}$ in a phosphate-buffered saline (PBS) blocking solution containing $1 \%(\mathrm{w} / \mathrm{v})$ BSA, $0.2 \%(\mathrm{w} / \mathrm{v})$ powdered milk, $2 \%(\mathrm{v} / \mathrm{v})$ normal goat serum, $0.1 \mathrm{~mol}$ glycine $/ \mathrm{ml}, 0.2 \%(\mathrm{w} / \mathrm{v})$ sodium azide and $0.01 \%(\mathrm{v} / \mathrm{v})$ Triton X-100 (Wickramasinghe \& Albertini 1992).

A triple-labeling protocol was used for the detection of microtubules, microfilaments and chromatin by fluorescence microscopy (Herman et al. 1983). Oocytes were first incubated for $1 \mathrm{~h}$ at $37^{\circ} \mathrm{C}$ in a mixture of mouse monoclonal anti $\alpha$-tubulin and anti $\beta$-tubulin antibodies (Sigma) at a 1:1000 final dilution in PBS blocking solution. After two washes in $0.1 \%(\mathrm{w} / \mathrm{v})$ polyvinylpyrrolidone (PVP)/PBS at room temperature, oocytes were incubated at $37^{\circ} \mathrm{C}$ in PBS blocking solution alone for $30 \mathrm{~min}$, and then in a 1:150 dilution of a donkey anti-mouse fluorescein-conjugated IgG (Jackson ImmunoResearch, West Grove, PA, USA) for $45 \mathrm{~min}$ at $37^{\circ} \mathrm{C}$. Oocytes were washed again twice in $0.1 \%$ PVP/PBS, and incubated at $37^{\circ} \mathrm{C}$ for $30 \mathrm{~min}$ with $10 \mathrm{U}$ Texas Red-conjugated phalloi$\mathrm{din} / \mathrm{ml}$ (Molecular Probes, Eugene, OR, USA) to stain actin filaments. Finally, after extensive washing in $0.1 \%$ PVP/PBS, oocytes were incubated at room temperature for $15 \mathrm{~min}$ in $10 \mu \mathrm{g}$ Hoechst 33258/ml (Molecular Probes) and mounted in 50\% (v/v) glycerol/PBS containing $25 \mathrm{mg}$ sodium azide/ml.

\section{Microscopic analysis and scoring criteria}

Labeled oocytes were examined using a Zeiss IM-35 inverted epi-fluorescence microscope (Zeiss, Thornwood, NY, USA) fitted with filters selective for Hoechst, fluorescein and Texas Red and a 50W mercury lamp. Digital images were acquired using a Photometrics Cool Snap CCD camera (Roper Scientific Inc., Trenton, NJ, USA) running on Metamorph software (version 5.0; Universal Imaging Corp., Downington, PA, USA).

For each oocyte, meiotic status, meiotic spindle orientation relative to the plasma membrane and presence of PB2 were recorded. Activation was considered to have occurred if the oocytes had exited MII arrest and resumed meiosis.

\section{Statistical analysis}

Each activation treatment was repeated at least three times on separate days in each strain of oocytes. Approximately 50 oocytes were examined per strain and treatment at each defined time-point, with the exception of the C57BL/6 strain (approximately 30 oocytes analyzed per time-point for each activation treatment). The results obtained in the replicate experiments were pooled and analyzed by chi-square test or Fisher's exact test. A probability value of $P<0.05$ was considered to be statistically significant.

\section{Results}

\section{Effect of oocyte genotype on meiotic cell cycle progression following ethanol exposure}

The majority of ethanol-treated oocytes, regardless of the strain, exited MII arrest during the first $20 \mathrm{~min}$ p.a. and reached the TII stage between $50 \mathrm{~min}$ and $1 \mathrm{~h} 20 \mathrm{~min}$ p.a. However, significant differences were detected in the kinetics of meiotic resumption and of All-TII transition depending on the genotype of the oocytes. Whereas a similar percentage of oocytes from the four strains were at early All stage by 5 min p.a. (46.4-64\%), a significantly higher number of $\mathrm{C} 57 \mathrm{BL} / 6$ oocytes were still at MII at $10 \mathrm{~min}(58.1 \%)$ and $20 \mathrm{~min}$ p.a. (32.3\%) when compared with CF-1 (26 and 10\% respectively) and NU/+ oocytes (33.3 and $6 \%$ respectively), indicating a slower release from MII arrest (Fig. 1). By 50 min after ethanol exposure, most B6D2F1 (98\%) and CF-1 (92.5\%) oocytes and 100\% of NU/+ oocytes had resumed meiosis, while $25.8 \%$ of C57BL/6 oocytes were still arrested at MII. The majority of CF-1 oocytes that had exited MII by $50 \mathrm{~min}$ p.a. were already at the TII stage (87.1\%), a percentage significantly higher than that of B6D2F1 (60\%) and NU/+ oocytes $(68.8 \%)$ but similar to that of $\mathrm{C} 57 \mathrm{BL} / 6$ oocytes $(78.3 \%)$. By $1 \mathrm{~h} 20 \mathrm{~min}$ p.a. and onward, no more differences were observed among genotypes in the rates of activation or in the percentage of activated oocytes that had progressed further than All. Therefore, in spite of the fact that C57BL/6 oocytes were slow to resume meiosis after ethanol activation treatment, they were quick to catch up. In fact, exit from TII after PB2 extrusion commenced earlier in C57BL/6 oocytes (1 h $20 \mathrm{~min}$ p.a.) than in CF-1 and $\mathrm{NU} /+$ oocytes (1 h 50 min p.a.) or in B6D2F1 oocytes (2 h $20 \mathrm{~min}$ p.a.). In addition, by $2 \mathrm{~h} 20 \mathrm{~min}$ after ethanol exposure, $30.8 \%$ of activated C57BL/6 oocytes had exited the TII stage, a percentage similar to that of CF-1 (10.4\%) and NU/+ oocytes (14\%) but significantly higher than that of B6D2F1 oocytes (1.9\%; Fig. 1).

Activated oocytes showed a different behavior in their meiotic progression after TII exit and PB2 extrusion depending on the strain. By $5 \mathrm{~h} 50 \mathrm{~min}$ p.a. $94 \%$ of activated B6D2F1 oocytes had progressed from TII into interphase and formed a pronucleus. However, in a significant and similar percentage of activated C57BL/6 (20\%), CF-1 (49\%) and NU/+ oocytes (37\%) a spindle formed around the condensed chromosomes after PB2 extrusion, and the oocytes became arrested at a new metaphase stage (MIII) (Figs 1 and $2 \mathrm{~h}$ ). 
B6D2F1

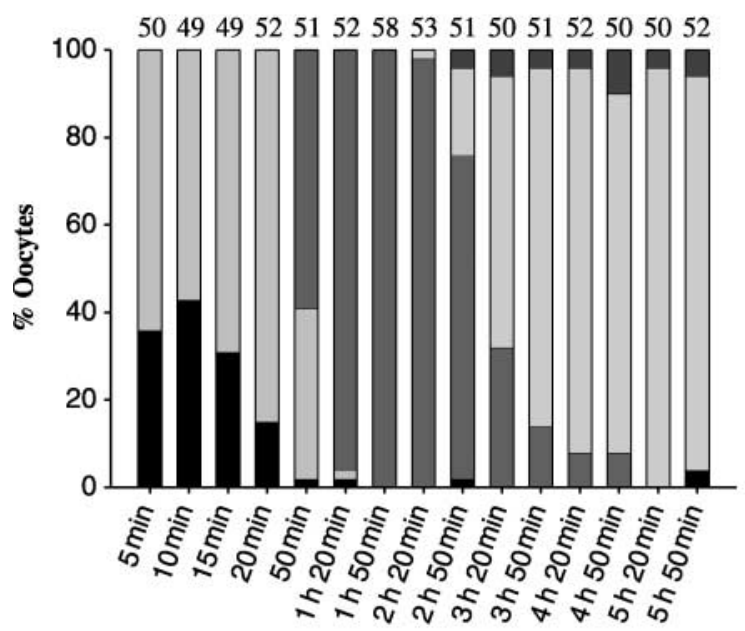

CF-1

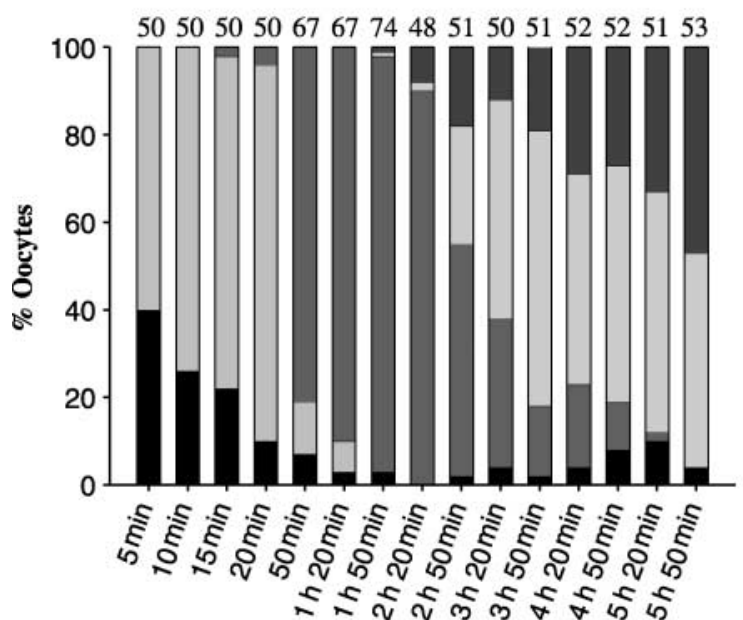

C57BL/6

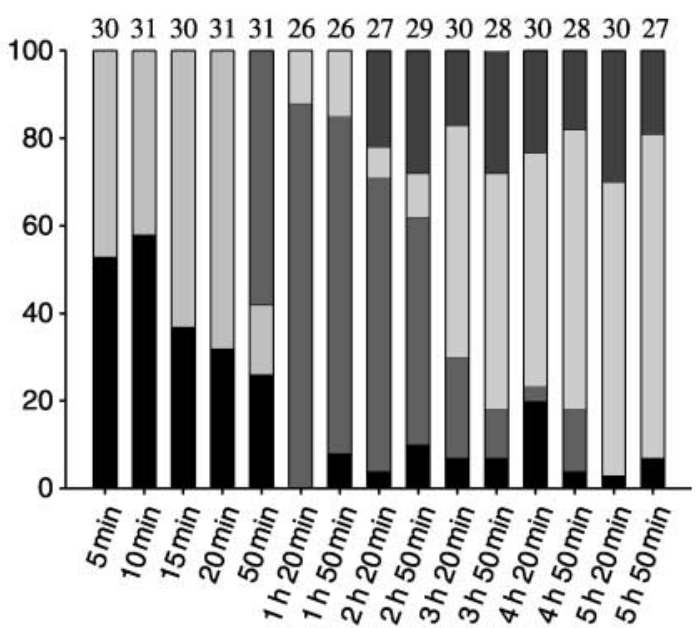

$\mathrm{NU} /+$

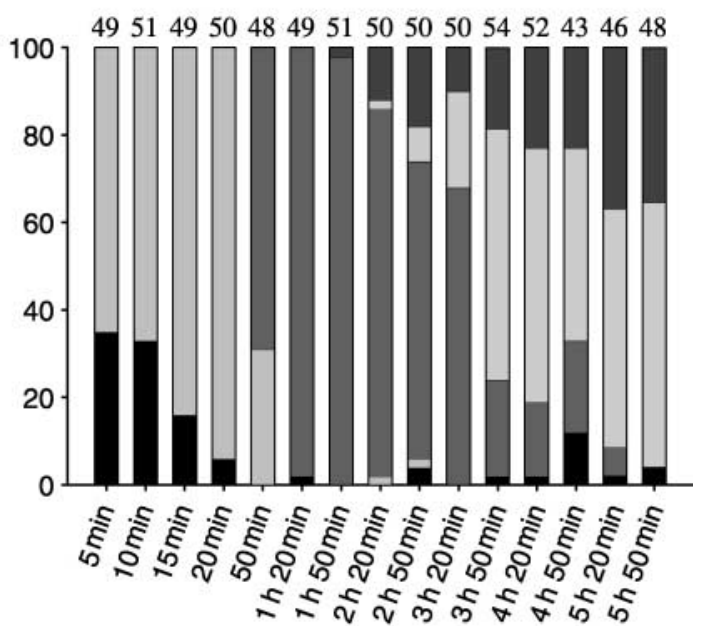

Time post-activation

$\square$ MII $\square$ All $\square$ TII $\square$ Interphase $\square$ MIII

Figure 1 Meiotic cell cycle resumption and progression in mouse oocytes from hybrid B6D2F1, inbred C57BL/6, outbred CF-1 and immunodeficient mutant nude (NU/+) females after parthenogenetic activation with ethanol. Data at each time-point represent the combined results of at least three replicate experiments. Numbers at the top of the columns indicate the total number of oocytes analyzed at each time-point

\section{Effect of oocyte genotype on meiotic cell cycle progression following strontium exposure}

When strontium was used as the activating agent, no differences were observed between genotypes in the speed of meiotic resumption during the first $20 \mathrm{~min}$ after treatment (Fig. 3). However, from 50 min p.a. and onward, NU/+ oocytes displayed the lowest activation rates, except for some groups of C57BL/6 oocytes (50 min, $2 \mathrm{~h} 20 \mathrm{~min}$ and $2 \mathrm{~h} 50 \mathrm{~min}$ ). Progression from All to TIl between $50 \mathrm{~min}$ and $2 \mathrm{~h} 50 \mathrm{~min}$ p.a. was also delayed in NU/+ oocytes when compared with B6D2F1 and CF-1 oocytes, which also showed higher percentages of activated oocytes in TII by 50 min p.a. (93.1 and
$94.2 \%$ respectively) than in the $\mathrm{C} 57 \mathrm{BL} / 6$ strain $(62.5 \%$; Fig. 3).

As previously observed with ethanol, strontium-treated C57BL/6 oocytes were the earliest in exiting TII (starting at $1 \mathrm{~h} 20 \mathrm{~min}$ p.a.) and also the fastest until $2 \mathrm{~h} 50 \mathrm{~min}$ p.a. Whereas the first NU/+ oocytes to exit TII were detected at $2 \mathrm{~h} 20$ min p.a. (2.4\%), as in B6D2F1 (10\%) and in CF$1(1.9 \%)$ oocytes, the timing of the TII-interphase transition between $2 \mathrm{~h} 50 \mathrm{~min}$ and $3 \mathrm{~h} 50 \mathrm{~min}$ was significantly delayed in this strain. At $5 \mathrm{~h} 50 \mathrm{~min}$ p.a., however, 100\% of the oocytes that were activated had progressed further than the TIl stage, regardless of the genotype. All activated B6D2F1 and CF-1 oocytes and $97.8 \%$ of activated NU/+ 

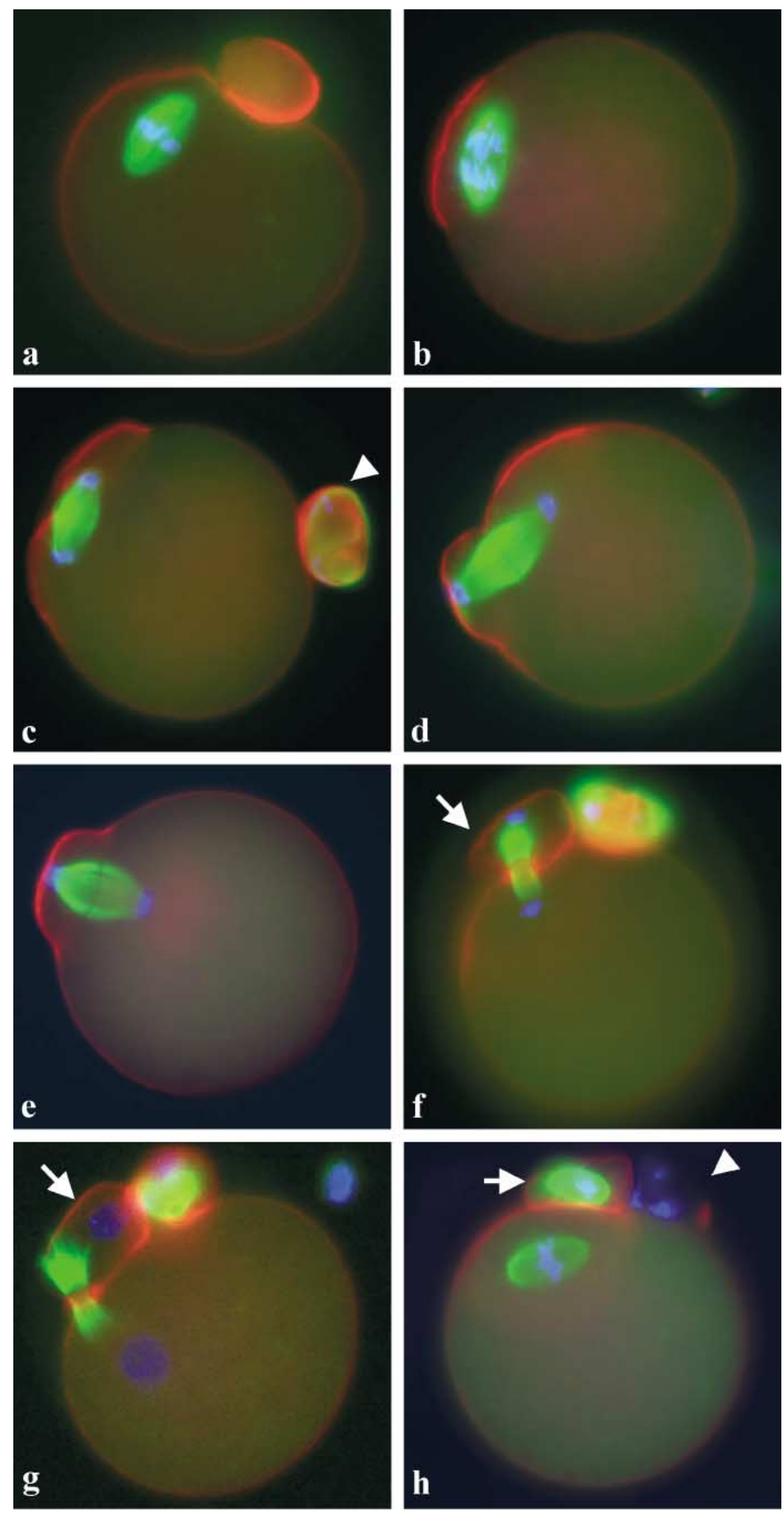

Figure 2 Sequential images of meiotic cell cycle progression, spindle rotation and PB2 extrusion in parthenogenetically activated mouse oocytes. MII arrested oocytes (a) were treated with either ethanol or strontium and fixed at several time-points after activation. Microtubules (green), microfilaments (red) and chromatin (blue) were stained with anti-tubulin antibodies, phalloidin and Hoechst 33258 respectively. Although differences in timing were detected depending on the strain of the oocyte and the activating stimulus (see text for details), a significant percentage of oocytes had resumed meiosis and were found at early All stage by $5 \mathrm{~min}$ p.a. (b). As the oocytes progressed from All to TII, two cortical protrusions formed on top of each pole of the spindle, which was initially parallel to plasma membrane (c). As early as 15-20 min p.a. the spindle started to rotate towards one of the protrusions, which enlarged as the other one regressed (d). By 50 min p.a. only a single cortical protrusion was evident in some of the activated oocytes, and the telophase spindle showed an orientation perpendicular to the plasma membrane (e). Between $1 \mathrm{~h}$ $20 \mathrm{~min}$ and $1 \mathrm{~h} 50 \mathrm{~min}$ p.a. PB2 extrusion had occurred in the majority of the activated oocytes (f). Depending on the strain and the activating stimulus applied, activated oocytes progressed from TII to interphase after PB2 extrusion and formed a pronucleus (g), or became arrested at a new metaphase stage (MIII) and a new metaphase spindle formed (h).

Arrowheads and arrows indicate the presence of the first and the second PB respectively. Original magnification 400x. 
B6D2F1

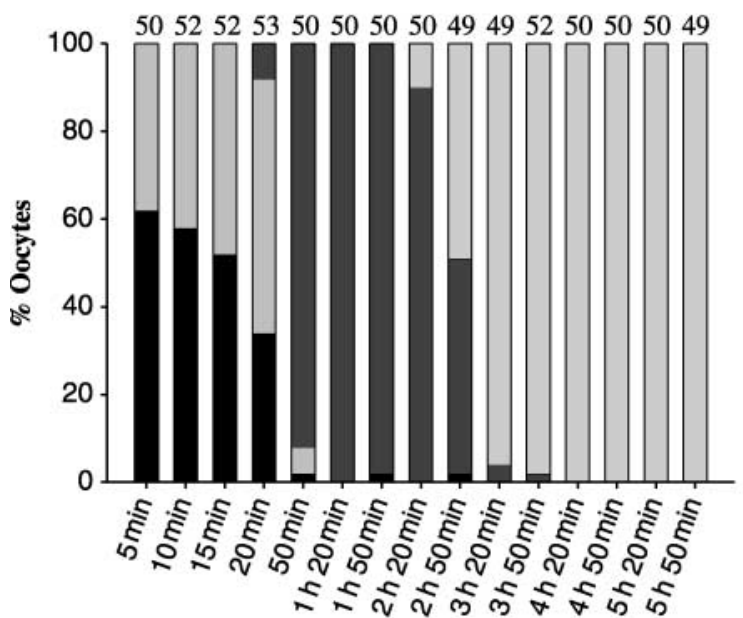

CF-1

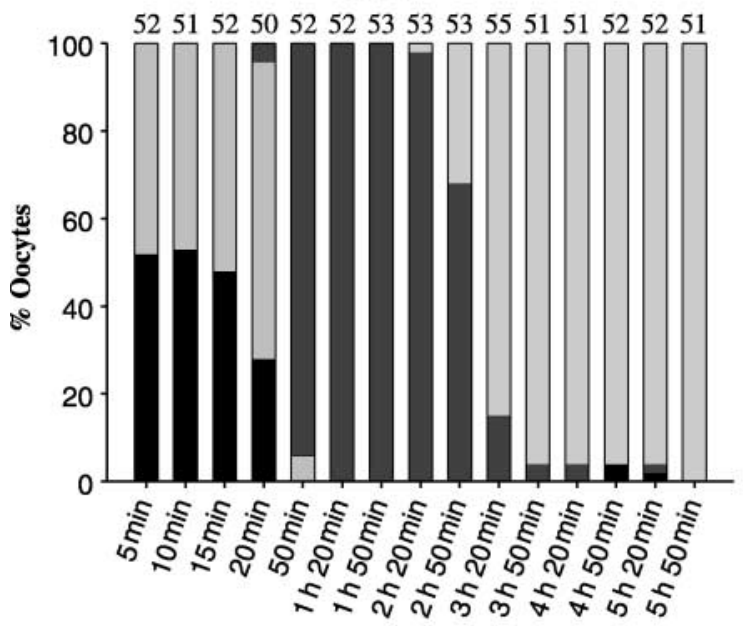

C57BL/6

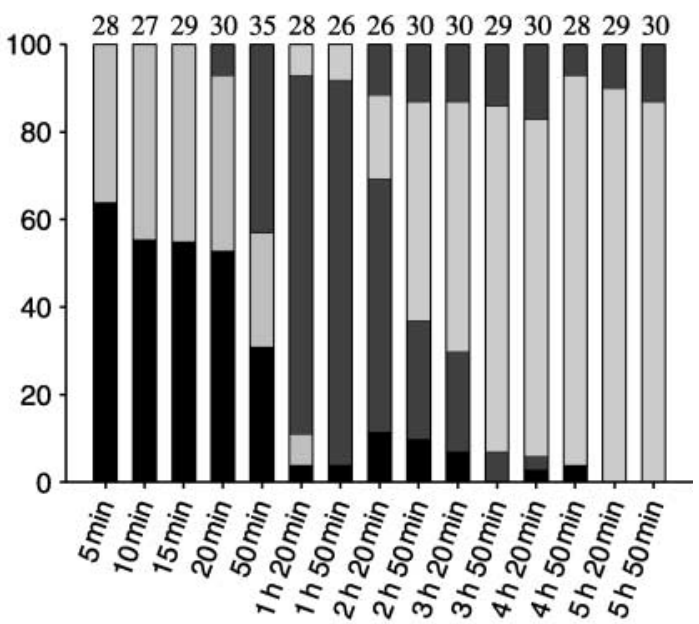

NU/+

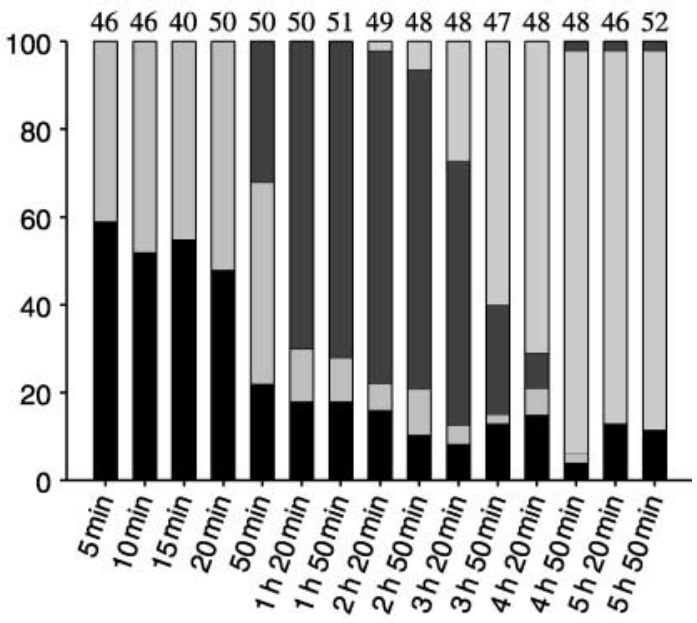

Time post-activation

$\square$ MII $\square$ All $\square$ TII $\square$ Interphase $\square$ MIII

Figure 3 Meiotic cell cycle resumption and progression in mouse oocytes from hybrid B6D2F1, inbred C57BL/6, outbred CF-1 and outbred immunodeficient nude (NU/+) females after parthenogenetic activation with strontium. Data at each time-point represent the combined results of at least three replicate experiments. Numbers at the top of the columns indicate the total number of oocytes analyzed at each time-point.

oocytes were in interphase at this point, while a significant number of activated C57BL/6 oocytes $(13.3 \%)$ remained arrested at $\mathrm{MIII}$ and only $86.7 \%$ were able to form a pronucleus (Fig. 3).

\section{Effect of the activating stimulus on meiotic cell cycle progression following parthenogenetic activation}

In comparison with ethanol, meiotic resumption during the first $20 \mathrm{~min}$ after strontium exposure was significantly delayed in B6D2F1, CF-1 and NU/+ oocytes, but not in C57BL/6 oocytes. In addition, in the NU/+ strain, the percentage of activated oocytes between $50 \mathrm{~min}(78 \%)$ and 2 h 20 min p.a. (83.7\%) was significantly lower than when ethanol was used as the activating agent (100\%), and the All-TII transition between $50 \mathrm{~min}$ and $1 \mathrm{~h} 50 \mathrm{~min}$ p.a. was also delayed. By contrast, in activated B6D2F1 oocytes, progression from All to TII at $20 \mathrm{~min}$ and $50 \mathrm{~min}$ p.a. was faster when strontium rather than ethanol was used as the activating stimulus (Figs 1 and 3).

Differences between activation protocols were also observed in the timing and the speed of TII exit, but only for B6D2F1, CF-1 and NU/+ oocytes. In the B6D2F1 strain, the first activated oocytes that exited TII after strontium exposure were detected at 2 h 20 min p.a. (10\%), as when ethanol activation treatment was applied (1.9\%). However, a significantly higher percentage of strontium- than of 
ethanol-treated oocytes had formed a pronucleus by $2 \mathrm{~h}$ $50 \mathrm{~min}$ and $3 \mathrm{~h} 20 \mathrm{~min}$ p.a. (50 vs $24 \%$ and 95.9 vs $68 \%$ respectively). Therefore, the $\mathrm{TII}-$ interphase transition was accelerated in strontium-treated B6D2F1 oocytes when compared with the ethanol-treated group. A similar pattern was observed in the CF-1 strain. Although the first strontium-treated CF-1 oocytes to exit TII were detected $30 \mathrm{~min}$ later than when ethanol was used as the activating stimulus ( 2 h 20 min vs 1 h 50 min), the difference was not significant, and the percentage of activated oocytes that had exited TII by $3 \mathrm{~h} 20 \mathrm{~min}, 4 \mathrm{~h} 20 \mathrm{~min}$ and $4 \mathrm{~h} 50 \mathrm{~min}$ was significantly higher after strontium than after ethanol exposure (85.4 vs $64.6 \%, 96.1$ vs $80 \%$ and 100 vs $87.5 \%$ respectively). Likewise, TII exit was delayed for $30 \mathrm{~min}$ in strontium-treated $\mathrm{NU} /+$ oocytes in comparison with the ethanol-treated group ( $2 \mathrm{~h} 20 \mathrm{~min}$ vs $1 \mathrm{~h} 50 \mathrm{~min}$ ). However, no significant differences were detected in this strain in the speed of the TIIinterphase transition between the two activation protocols, except for a slight delay at $2 \mathrm{~h} 50 \mathrm{~min}$ p.a. and a slight acceleration at $4 \mathrm{~h} 50 \mathrm{~min}$ p.a. in the strontium-treated oocytes.

For all genotypes, strontium treatment resulted in an increase in the rate of pronuclear formation in comparison with ethanol, although this increase was only significant for the CF-1 and NU/+ strains. Thus, by $5 \mathrm{~h} 50 \mathrm{~min}$ after strontium exposure, $100 \%$ of CF-1 and $97.8 \%$ of NU/+ activated oocytes had formed a pronucleus, a percentage significantly higher than that observed when ethanol was applied (51 and $63 \%$ respectively). In contrast, $13.3 \%$ of activated C57BL/6 oocytes were arrested at MIII by $5 \mathrm{~h}$ $50 \mathrm{~min}$ after strontium exposure, a percentage equivalent to that obtained in oocytes from the same strain treated with ethanol $(20 \%)$.

\section{Effect of oocyte genotype and activating stimulus on meiotic spindle rotation following parthenogenetic activation}

In MIl-arrested oocytes, the spindle was parallel to the plasma membrane. Shortly after activation, as the oocyte exits MII and progresses to AII and subsequently to TII, the sister chromatids migrated to opposite poles of the spindle and two cortical protrusions formed adjacent to each spindle pole. The meiotic spindle then started rotating towards one of the protrusions, as the other one regressed, and achieved an orientation perpendicular to the plasma membrane. Eventually, this protrusion was constricted at the oolemma and the PB2 containing half of the chromatin of the oocyte was extruded (Fig. 2).

Initiation of spindle rotation after ethanol exposure followed a similar timing in the four strains of oocytes analyzed, but significant differences were detected in the rate of completion of the rotation depending on the genotype of the oocyte. Specifically, completion of spindle rotation was significantly slower in NU/+ oocytes than in the other three strains (Table 1). In addition, even though CF-1 oocytes were faster than B6D2F1 oocytes to progress from All to TII (Fig. 1), they were significantly slower to complete spindle rotation (Table 1). By 2 h 50 min p.a. almost all activated oocytes $(92-100 \%$ ) showed a perpendicularly oriented spindle and no more significant differences in the kinetics of spindle rotation were detected among genotypes from this time-point and onward (data not shown).

When compared with ethanol, strontium induced an acceleration of partial spindle rotation in B6D2F1 oocytes at 50 min p.a., but by $1 \mathrm{~h} 20$ min p.a. a significantly lower number of strontium- than of ethanol-treated oocytes had completed spindle rotation (Tables 1 and 2). Completion of spindle rotation was also delayed in strontium-treated C57BL/6 oocytes at $1 \mathrm{~h} 20 \mathrm{~min}$ p.a. and in CF-1 oocytes at $50 \mathrm{~min}$ p.a., relative to ethanol exposure. In addition, in the NU/+ strain, both the rate of partial spindle rotation at $50 \mathrm{~min}$ p.a. and the rate of complete spindle rotation at $1 \mathrm{~h} 20 \mathrm{~min}$ and $1 \mathrm{~h} 50 \mathrm{~min}$ p.a. was decreased in strontium-treated oocytes in comparison with ethanol-treated oocytes of the same strain. In fact, NU/+ oocytes were the slowest again of all groups of strontium-treated oocytes both to initiate and to complete spindle rotation (Table 2).

Table 1 Number (\% in parentheses) of activated mouse oocytes showing a partially or completely rotated meiotic spindle at various times after ethanol exposure.

\begin{tabular}{|c|c|c|c|c|c|c|c|c|}
\hline \multirow[b]{2}{*}{ Category } & \multirow[b]{2}{*}{ Strain } & \multicolumn{7}{|c|}{ Time post-activation } \\
\hline & & $15 \mathrm{~min}$ & $20 \min$ & $50 \mathrm{~min}$ & $1 \mathrm{~h} 20 \mathrm{~min}$ & $1 \mathrm{~h} 50 \mathrm{~min}$ & $2 \mathrm{~h} 20 \mathrm{~min}$ & $2 \mathrm{~h} 50 \mathrm{~min}$ \\
\hline \multirow{4}{*}{$\begin{array}{l}\text { Oocytes with partially } \\
\text { rotated spindle }\end{array}$} & B6D2F1 & $0 / 34(0)$ & $1 / 44(2)$ & $12 / 50(24)$ & $1 / 51(2)^{\mathrm{a}}$ & $0 / 58(0)$ & $0 / 53(0)$ & $0 / 50(0)$ \\
\hline & $\mathrm{C} 57 \mathrm{BL} / 6$ & $1 / 19(5)$ & $1 / 21(5)$ & $8 / 23(35)$ & $2 / 26(8)^{a, b}$ & $0 / 24(0)$ & $0 / 26(0)$ & $0 / 26(0)$ \\
\hline & CF-1 & $0 / 39(0)$ & $2 / 45$ (4) & $19 / 62(31)$ & $3 / 65(5)^{\mathrm{a}}$ & $1 / 72(1)$ & $0 / 48(0)$ & $0 / 50(0)$ \\
\hline & $\mathrm{NU} /+$ & $0 / 41(0)$ & $0 / 47(0)$ & $21 / 48(44)$ & $13 / 48(27)^{\mathrm{b}}$ & $2 / 51(4)$ & $1 / 50(2)$ & $0 / 48(0)$ \\
\hline \multirow{4}{*}{$\begin{array}{l}\text { Oocytes with completely } \\
\text { rotated spindle }\end{array}$} & B6D2F1 & $0 / 34(0)$ & $0 / 44(0)$ & $20 / 50(40)^{\mathrm{a}}$ & $50 / 51(98)^{\mathrm{a}}$ & $58 / 58(100)^{a}$ & $53 / 53(100)^{\mathrm{a}}$ & $49 / 50(98)$ \\
\hline & C57BL/6 & $0 / 19(0)$ & $0 / 21(0)$ & $10 / 23(43)^{\mathrm{a}}$ & $24 / 26(92)^{a, b}$ & $24 / 24(100)^{a, b}$ & $25 / 26(96)^{a, b}$ & $26 / 26(100)$ \\
\hline & CF-1 & $0 / 39(0)$ & $0 / 45(0)$ & $22 / 62(35)^{\mathrm{a}}$ & $52 / 65(80)^{b}$ & $63 / 72(87)^{b}$ & $40 / 48(83)^{\mathrm{b}}$ & $46 / 50(92)$ \\
\hline & $\mathrm{NU} /+$ & $0 / 41(0)$ & $0 / 47(0)$ & $0 / 48(0)^{b}$ & $29 / 48(60)^{\mathrm{c}}$ & $45 / 51(88)^{b}$ & $47 / 50(94)^{a, b}$ & $45 / 48(94)$ \\
\hline \multirow{4}{*}{$\begin{array}{l}\text { Total oocytes with } \\
\text { rotated spindle } \\
\text { (partially + completely) }\end{array}$} & B6D2F1 & $0 / 34(0)$ & $1 / 44(2)$ & $32 / 50(64)^{a, b}$ & $51 / 51(100)^{\mathrm{a}}$ & $58 / 58(100)^{\mathrm{a}}$ & $53 / 53(100)^{\mathrm{a}}$ & $49 / 50(98)$ \\
\hline & $\mathrm{C} 57 \mathrm{BL} / 6$ & $1 / 19(5)$ & $1 / 21(5)$ & $18 / 23(78)^{\mathrm{a}}$ & $26 / 26(100)^{a, b}$ & $24 / 24(100)^{a, b}$ & $25 / 26(96)^{a, b}$ & $26 / 26(100)$ \\
\hline & CF-1 & $0 / 39(0)$ & $2 / 45(4)$ & $41 / 62(66)^{\mathrm{a}}$ & $55 / 65(85)^{b}$ & $64 / 72(89)^{b}$ & $40 / 48(83)^{\mathrm{b}}$ & $46 / 50(92)$ \\
\hline & $\mathrm{NU} /+$ & $0 / 41(0)$ & $0 / 47(0)$ & $21 / 48(44)^{\mathrm{b}}$ & $42 / 48(87)^{b}$ & $47 / 51(92)^{a, b}$ & $48 / 50(96)^{a}$ & $45 / 48(94)$ \\
\hline
\end{tabular}

\footnotetext{
${ }^{\mathrm{a}-\mathrm{c}}$ Values with different superscripts within the same column and category differ significantly between strains $(P<0.05)$.
} 
Table 2 Number (\% in parentheses) of activated mouse oocytes showing a partially or completely rotated meiotic spindle at various times after strontium exposure.

\begin{tabular}{|c|c|c|c|c|c|c|c|c|}
\hline \multirow[b]{2}{*}{ Category } & \multirow[b]{2}{*}{ Strain } & \multicolumn{7}{|c|}{ Time post-activation } \\
\hline & & $15 \mathrm{~min}$ & $20 \mathrm{~min}$ & $50 \mathrm{~min}$ & $1 \mathrm{~h} 20 \mathrm{~min}$ & $1 \mathrm{~h} 50 \mathrm{~min}$ & $2 \mathrm{~h} 20 \mathrm{~min}$ & $2 \mathrm{~h} 50 \mathrm{~min}$ \\
\hline \multirow{4}{*}{$\begin{array}{l}\text { Oocytes with partially } \\
\text { rotated spindle }\end{array}$} & B6D2F1 & $0 / 25(0)$ & $1 / 35$ & $23 / 49(47)^{\mathrm{a}}$ & 10/50 (20) & $1 / 49(2)^{\mathrm{a}}$ & $0 / 50(0)^{\mathrm{a}}$ & 0/48 (0) \\
\hline & C57BL/6 & $2 / 13(15)$ & $2 / 14(14)$ & $7 / 24(29)^{a, b}$ & $7 / 27(26)$ & $0 / 25(0)^{a}$ & $0 / 23(0)^{a}$ & $0 / 27(0)$ \\
\hline & CF-1 & $0 / 27(0)$ & 0/36 (0) & $19 / 52(36)^{a}$ & $8 / 52(16)$ & $2 / 53(4)^{a}$ & $6 / 53(11)^{b}$ & 0/53 (0) \\
\hline & $\mathrm{NU} /+$ & $0 / 22(0)$ & $0 / 26(0)$ & $4 / 39(10)^{b}$ & $14 / 41(34)$ & $10 / 42(24)^{b}$ & $1 / 41(2)^{a, b}$ & $0 / 43(0)$ \\
\hline \multirow{4}{*}{$\begin{array}{l}\text { Oocytes with completely } \\
\text { rotated spindle }\end{array}$} & B6D2F1 & $0 / 25(0)$ & $0 / 35(0)$ & $11 / 49(22)^{a, c}$ & $39 / 50(78)^{a}$ & $47 / 49(96)^{a}$ & $50 / 50(100)^{a}$ & $48 / 48(100)^{\mathrm{a}}$ \\
\hline & C57BL/6 & $0 / 13(0)$ & $0 / 14(0)$ & $7 / 24(29)^{c}$ & $18 / 27(67)^{a}$ & $24 / 25(96)^{a}$ & $23 / 23(100)^{a, b}$ & $26 / 27(96)^{a, b}$ \\
\hline & CF-1 & $0 / 27(0)$ & $0 / 36(0)$ & $4 / 52(8)^{\mathrm{a}}$ & $40 / 52(77)^{\mathrm{a}}$ & $49 / 53(92)^{\mathrm{a}}$ & $45 / 53(85)^{b}$ & $53 / 53(100)^{\mathrm{a}}$ \\
\hline & $\mathrm{NU} /+$ & $0 / 22(0)$ & $0 / 26(0)$ & $0 / 39(0)^{b}$ & $14 / 41(34)^{b}$ & $27 / 42(64)^{b}$ & $36 / 41(88)^{b}$ & $37 / 43(86)^{b}$ \\
\hline \multirow{4}{*}{$\begin{array}{l}\text { Total oocytes with } \\
\text { rotated spindle } \\
\text { (partially + completely) }\end{array}$} & $\mathrm{B} 6 \mathrm{D} 2 \mathrm{~F} 1$ & $0 / 25(0)$ & $1 / 35(3)$ & $34 / 49(69)^{a}$ & $49 / 50(98)^{a}$ & $48 / 49$ & $50 / 50(100)^{\mathrm{a}}$ & $48 / 48(100)^{a}$ \\
\hline & $\mathrm{C} 57 \mathrm{BL} / 6$ & $2 / 13$ & 2/14 (14) & $14 / 24(58)^{a, b}$ & $25 / 27(93)^{b}$ & $24 / 25(96)$ & $23 / 23(100)^{a, b}$ & $26 / 27(96)^{a, b}$ \\
\hline & CF-1 & $0 / 27(0)$ & $0 / 36(0)$ & $23 / 52(44)^{b}$ & $48 / 52(92)^{\mathrm{a}}$ & $51 / 53(96)$ & $51 / 53(96)^{a, b}$ & $53 / 53(100)^{a}$ \\
\hline & $\mathrm{NU} /+$ & $0 / 22(0)$ & $0 / 26(0)$ & $4 / 39(10)^{\mathrm{C}}$ & $28 / 41(68)^{b}$ & $37 / 42(88)$ & $37 / 41(90)^{b}$ & $37 / 43(86)^{b}$ \\
\hline
\end{tabular}

${ }^{a-c}$ Values with different superscripts within the same column and category differ significantly between strains $(P<0.05)$.

\section{Effect of oocyte genotype and activating stimulus on the timing of PB2 extrusion following parthenogenetic activation}

The presence of an extruded PB2 was first detected by $50 \mathrm{~min}$ after ethanol exposure (16\% B6D2F1, 13\% C57BL/6, 9.7\% CF-1), except in the NU/+ strain (Fig. 4a). Extrusion of PB2 was in fact delayed in NU/+ oocytes, relative to the other oocyte genotypes, until $2 \mathrm{~h} 20 \mathrm{~min}$ p.a. No significant differences were detected in the timing of PB2 extrusion among the other three genotypes, except for a lower percentage of CF-1 activated oocytes showing an extruded PB2 by $1 \mathrm{~h} 20 \mathrm{~min}(72 \%$ in CF-1 vs $96 \%$ in B6D2F1 and $88 \%$ in C57BL/6 oocytes; Fig. 4a).

Strontium caused a delay in the rates of PB2 extrusion by $1 \mathrm{~h} 20 \mathrm{~min}$ and $1 \mathrm{~h} 50 \mathrm{~min}$ in B6D2F1 and CF-1 oocytes when compared with ethanol. However, no significant differences in the timing of $\mathrm{PB} 2$ extrusion were detected among B6D2F1, C57BL/6 or CF-1 oocytes treated with strontium (Fig. 4b). Strontium also resulted in a delayed extrusion of the PB2 in NU/+ oocytes when compared with ethanol, although it was only significant by $1 \mathrm{~h}$ $50 \mathrm{~min}$ and $3 \mathrm{~h} 20 \mathrm{~min}$ p.a. In comparison with the other three genotypes, strontium-treated NU/+ oocytes showed the lowest rates of PB2 extrusion between $1 \mathrm{~h} 20 \mathrm{~min}$ and $3 \mathrm{~h} 20$ min p.a. (Fig. 4b).

By $3 \mathrm{~h} 50$ min p.a. extrusion of PB2 had occurred in the majority $(96-100 \%)$ of both ethanol- and strontium-treated oocytes and no more differences were observed either among genotypes or between activation treatments in the rates of PB2 extrusion from this time-point and onward (data not shown).

\section{Discussion}

In this work, experiments were undertaken to investigate the effects of oocyte genotype and activating stimulus on the kinetics of key nuclear events of oocyte activation, such as meiotic cell cycle resumption and progression,

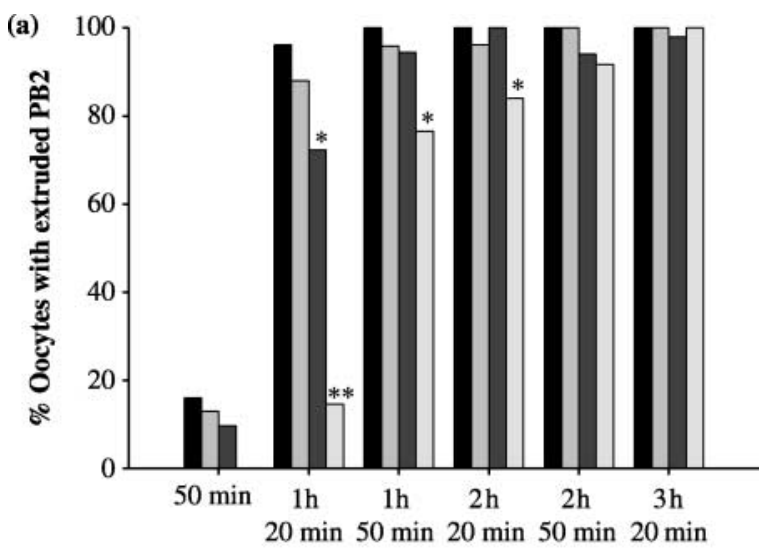

Time post-activation

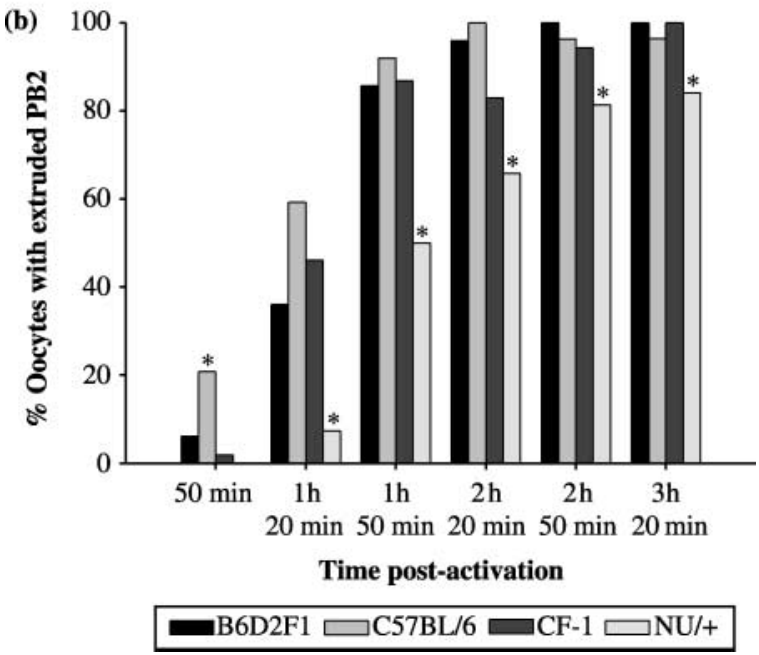

Figure 4 Rates of PB2 extrusion at various times p.a. in (a) ethanoland (b) strontium-treated mouse oocytes from four different strains. Data at each time-point represent the combined results of at least three replicate experiments. Asterisks at the top of the columns denote significant differences $(P<0.05)$ among strains at each timepoint. 
spindle rotation and PB2 extrusion. With this aim, oocytes collected from hybrid B6D2F1, inbred $\mathrm{C} 57 \mathrm{BL} / 6$ and outbred $\mathrm{CF}-1$ and immunodeficient NU/+ mice were parthenogenetically activated with either ethanol or strontium and analyzed at several time-points after activation. These two artificial activating agents were chosen because of the differential $\mathrm{Ca}^{2+}$ signal dynamics they induce in the treated oocytes (Cuthbertson et al. 1981, Kline \& Kline 1992, Bos-Mikich et al. 1995).

No differences were detected among strains or between activation treatments in the final activation efficiency, measured as the percentage of oocytes that exited MII arrest by $6 \mathrm{~h}$ p.a., except for the group of strontium-treated $\mathrm{NU} /+$ oocytes. However, significant differences were evident in the timing of meiotic cell cycle progression and in the rate of pronuclear formation after activation depending on both the oocyte genotype and the activating stimulus. In fact, comparison of the kinetics of oocyte activation in oocytes from four different strains of mice subjected to two different activation treatments allowed us to identify some strain-specific characteristics that appear to be independent of the activating stimulus and other characteristics that vary according to the activation treatment applied. For instance, fast exit from the TII stage after PB2 extrusion and arrest at MIII appear as inherent characteristics of C57BL/6 oocytes, at least under the artificial activation conditions examined in the present study, as they are not modified by the type of activating stimulus applied. In contrast, delayed meiotic resumption and progression in NU/+ oocytes was only related to strontium exposure. In addition, the low percentage of CF-1 and $\mathrm{NU} /+$ oocytes that were able to progress to interphase and form a pronucleus after PB2 extrusion following ethanol exposure could be significantly improved by the use of strontium as the activating stimulus. Nevertheless, in spite of the clear influence of the activating stimulus on the timing of meiotic progression in NU/+ oocytes and in the rate of pronuclear formation in both NU/+ and CF-1 oocytes, the genetic background of the oocyte must also play a role, as these effects are not observed in oocytes from hybrid B6D2F1 and inbred $\mathrm{C} 57 \mathrm{BL} / 6$ strains.

Because the mechanism of action of various artificial activating stimuli is well known, some of the effects of the activation treatment on the kinetics and the end-point of meiotic progression observed in this study are easily explained. Thus, while ethanol induces a single, large $\mathrm{Ca}^{2+}$ rise for the period of its addition (Cuthbertson et al. 1981), strontium triggers repetitive $\mathrm{Ca}^{2+}$ rises which last for several hours (Kline \& Kline 1992, Bos-Mikich et al. 1995). Even though a single $\mathrm{Ca}^{2+}$ increase is sufficient to induce early activation events, such as cortical granule exocytosis and the resumption of meiosis, repetitive $\mathrm{Ca}^{2+}$ oscillations are required for late events such as mRNA recruitment, pronuclear formation and DNA synthesis to occur (Schultz \& Kopf 1995, Soloy et al. 1997). In fact, our results in CF-1, NU/+ and C57BL/6 oocytes agreed with previous findings that oocytes treated with ethanol or other activating agents inducing a single $\mathrm{Ca}^{2+}$ rise often arrest at MIII instead of forming a pronucleus after PB2 extrusion, due to insufficient stimulation (Kubiak 1989, Vincent et al. 1992). Similarly, the significant increase in the rates of pronuclear formation in $\mathrm{CF}-1$ and NU/+ oocytes as seen after strontium exposure was consistent with the idea that repetitive $\mathrm{Ca}^{2+}$ oscillations are instrumental in ensuring the completion of meiosis (Swann \& Ozil 1994, Ducibella et al. 2002). However, the high number of B6D2F1 oocytes that formed a pronucleus and of C57BL/6 oocytes that arrested at MIII after PB2 extrusion, irrespective of the activating stimulus applied, suggest that these rules are not absolute. In light of our results, the genetic background of the oocyte may also dictate the dynamics of the $\mathrm{Ca}^{2+}$ signal that is needed for a complete activation of the oocyte under artificial conditions. In particular, for the strains analyzed in this study, pronuclear formation in B6D2F1 oocytes appeared to require the lower $\mathrm{Ca}^{2+}$ stimulation and $\mathrm{C} 57 \mathrm{BL} / 6$ oocytes the higher.

On the other hand, because ethanol induces a large $\mathrm{Ca}^{2+}$ rise for the period of the oocyte exposure, it presumably results in a higher intensity of $\mathrm{Ca}^{2+}$ stimulation than strontium during the first minutes p.a. However, in the long term, the continued $\mathrm{Ca}^{2+}$ transients induced by strontium over a longer time-period probably contribute to a higher overall $\mathrm{Ca}^{2+}$ stimulation in the oocytes. This differential $\mathrm{Ca}^{2+}$ signal dynamics triggered by the two activating agents may account for the faster meiotic resumption observed in ethanol-treated B6D2F1, CF-1 and NU/+ oocytes during the first 20 min p.a., when compared with strontium exposure, and the faster TII exit in strontiumtreated B6D2F1 and CF-1 oocytes in comparison with ethanol-treated oocytes of the same genotype. The latter is consistent with the observations by Ozil $(1990,1998)$ that an increase in the intensity of the $\mathrm{Ca}^{2+}$ stimulation decreases the time to pronuclear formation after oocyte activation. Nevertheless, this effect was not observed for all the strains analyzed (e.g. C57BL/6 oocytes), thus indicating again an influence of the oocyte genetic background.

Our study also revealed strain- and treatment-dependent differences in the timing of spindle rotation and of PB2 extrusion after parthenogenetic activation. Strontium exposure resulted in a delay in the completion of spindle rotation and in PB2 extrusion in B6D2F1, CF-1 and NU/+ oocytes when compared with ethanol exposure. Also, $\mathrm{NU} /+$ oocytes were significantly slower than oocytes from the other three genotypes in completing meiotic spindle rotation and in extruding the PB2, both after ethanol and strontium treatment. In general, a positive correlation was observed between the apparent rate of spindle rotation and the rate of PB2 extrusion. This finding is not surprising as the spindle needs to achieve the proper orientation, perpendicular to the plasma membrane, before extrusion of the PB2 can occur. 
Earlier studies on the development of androgenetic mouse embryos have revealed strain-specific differences in how the oocytes modify paternal genomes after fertilization (Latham \& Solter 1991, Latham 1994, Latham \& Sapienza 1998). Similarly, maternal pronuclear exchanges between oocytes from different strains have also demonstrated a genotype effect on the modification of maternal chromosomes during oogenesis (Roemer et al. 1997). On the other hand, strain-specific differences in the timing of germinal vesicle breakdown and of first PB extrusion have been reported among oocytes derived from recombinant strains and progenitor inbred strains (Polanski 1997a,b). Finally, with regard to parthenogenesis, differences in the rate of cleavage after parthenogenetic activation using several treatments have been described in oocytes derived from two different outbred mouse strains (Marcus 1990). In addition, in a more recent study, oocytes of different strains (B6D2F1, C57BL/6 and DBA/2) have shown a different ability to support both parthenogenetic and cloned embryo development in different culture media (Gao et al. 2004). The origin of the oocyte strain-specific differences detected in these previous studies, as well as in the present study, is unclear, but it may reflect differences in ooplasm composition. The finding of at least 17 proteins showing significant quantitative differences in the rate of synthesis between inbred DBA/2 and C57BL/6 oocytes (Latham 1994) would support this idea.

Considering this egg composition effect, several possibilities could account for the strain-specific differences detected here on the timing and end-point of meiotic progression after parthenogenetic activation. Among them, it is possible that oocytes from different genotypes show differences in the size, density and properties of the $\mathrm{Ca}^{2+}$ channels located in the endoplasmatic reticulum resulting in quantitative or temporal differences in the $\mathrm{Ca}^{2+}$ transients induced by the activating stimulus. As the kinetics of cell cycle progression after activation and the choice between MIII arrest or progression to interphase is dependent on the profile of internal $\mathrm{Ca}^{2+}$ release in the oocyte after activation (Ozil 1990, 1998, Vincent et al. 1992), strain-dependent variations in the quantity of free $\mathrm{Ca}^{2+}$ liberated upon the same activation treatment could explain some of the genotype-specific differences detected in the present study. These variations could also be related to different oocyte maturation kinetics in the four mouse strains analyzed, as it has been reported that the amount of $I P_{3}$ receptor $\left(I_{3} R\right)$, a key channel in regulating intracellular $\mathrm{Ca}^{2+}$ oscillations during activation (Miyazaki et al. 1993), increases during meiotic maturation (Mehlmann et al. 1996, He et al. 1997). In fact, it is well documented in several mammalian species that complete activation and pronuclear formation is dependent upon the age of the oocyte with regard to ovulation. In general, while aged oocytes are easily activated even with artificial stimuli inducing a single $\mathrm{Ca}^{2+}$ rise, recently ovulated oocytes often arrest at MIII and repetitive $\mathrm{Ca}^{2+}$ transients or combined treatments with protein synthesis or phosphorylation inhibitors are required for the completion of meiosis and entry into interphase in these young oocytes (Collas et al. 1989, Kubiak et al. 1993, Presicce \& Yang 1994, Swann \& Ozil 1994, Krivokharchenko et al. 2003). Although it is beyond the scope of the present study, further analysis of oocyte maturation kinetics after hCG injection, quantification of $\mathrm{IP}_{3} \mathrm{R}$ levels and measurement of the $\mathrm{Ca}^{2+}$ transients induced by ethanol and strontium in oocytes from the four strains of mice could be performed to assess this possibility.

Alternatively, the proteins responsible for exit from MII arrest and pronuclear formation (i.e. MPF, MAPK, CaMKII) may possess different activation/inactivation thresholds in response to variations in the level or the dynamics of the intracellular $\mathrm{Ca}^{2+}$ concentration in oocytes from different strains. Likewise, oocytes from different genotypes might also differ in the time required for chromatin decondensation or for the assembly of the pronuclear envelope or of the contractile ring, due to quantitative or qualitative variations among strains in the proteins involved in these processes. This again could result in differences in the timing of TII exit and pronuclear formation or in the timing of PB2 extrusion depending on the genetic background of the oocyte.

Finally, it is interesting to note that hybrid B6D2F1 oocytes exhibited the best rates of pronuclear formation regardless of the activation treatment applied, indicating a better capacity for full activation than inbred C57BL/ 6 and outbred $\mathrm{CF}-1$ and NU/+ oocytes. In a recent study, Gao et al. (2004) showed that hybrid B6D2F1 oocytes were able to support better in vitro development to the blastocyst stage after parthenogenetic activation with strontium than inbred $\mathrm{C} 57 \mathrm{BL} / 6$ and $\mathrm{DBA} / 2$ oocytes. On the other hand, it is well documented that the rates of preimplantation embryo development both in vivo and in vitro are also strain dependent, and that embryos derived from hybrid strains develop more efficiently and faster than those derived from inbred and outbred strains (Goldbard \& Warner 1982, Warner et al. 1987, Du \& Wales 1993, Scott \& Whittingham 1996). Therefore, in light of these previous results by others and our results presented here, it is possible that strain-specific differences in the dynamics of oocyte activation could be related to later differences in the rate of early embryo development.

In conclusion, our results have demonstrated that the timing of nuclear events following oocyte activation, such as meiotic cell cycle progression, spindle rotation and PB2 extrusion, as well as the ability of the oocyte to complete activation and progress into interphase after PB2 extrusion depend not only on the parthenogenetic treatment applied but also on the genotype of the oocyte. Because of this, activation treatments that are efficient in oocytes from one strain may not necessarily be efficient for the full activation of oocytes from other strains. In particular, while the majority of B6D2F1 oocytes exit MII and progress to interphase after ethanol exposure, a relatively 
high proportion of C57BL/6, CF-1 and NU/+ oocytes become arrested at MIII. In a recent study, Kishikawa et al. (1999) reported similar parthenogenetic development up to the morula/blastocyst stage of B6D2F1 oocytes, irrespective of the activating stimulus applied (strontium, ethanol, electric pulse or sperm). However, the results might have been different if oocytes from a different strain (e.g. C57BL/6) had been used in the study. Identification of the specific ooplasmic factors that contribute to the genotype-specific differences in meiotic progression after activation and in parthenogenetic development should lead to a better understanding of the process of oocyte activation and may improve the efficiency of both artificial activation and cloning procedures.

\section{Acknowledgements}

The authors thank Victoria Huntress for technical assistance and acknowledge Charles River Laboratories for providing animals for this study. This work was supported by a Fulbright grant sponsored by the Spanish Ministry of Education, Culture \& Sports (to E I) and grants from USDA-NRI 2001-3520309966 (to E W O and D F A) and March of Dimes Birth Defects Foundation 01-248 (to D F A).

\section{References}

Alberio R, Zakhartchenko V, Motlik J \& Wolf E 2001 Mammalian oocyte activation: lessons from the sperm and implications for nuclear transfer. International Journal of Developmental Biology 45 797-809.

Bos-Mikich A, Swann K \& Whittingham DG 1995 Calcium oscillations and protein synthesis inhibition synergistically activate mouse oocytes. Molecular Reproduction and Development 41 84-90.

Bos-Mikich A, Whittingham DG \& Jones KT 1997 Meiotic and mitotic $\mathrm{Ca}^{2+}$ oscillations affect cell composition in resulting blastocysts. Developmental Biology 182 172-179.

Carroll DJ, Albay DT, Hoang KM, O'Neil FJ, Kumano M \& Foltz KR 2000 The relationship between calcium, MAPk, and DNA synthesis in the sea urchin egg at fertilisation. Developmental Biology 217 179-191.

Collas P, Balise JJ, Hofmann GA \& Robl JM 1989 Electrical activation of mouse oocytes. Theriogenology 332 835-844.

Collas P, Chang T, Long C \& Robl JM 1995 Inactivation of histone H1 kinase by $\mathrm{Ca}^{2+}$ in rabbit oocytes. Molecular Reproduction and Development 40 253-258.

Cuthbertson KS 1983 Parthenogenetic activation of mouse oocytes in vitro with ethanol and benzyl alcohol. Journal of Experimental Zoology 226 311-314.

Cuthbertson KS \& Cobbold PH 1985 Phorbol ester and sperm activate mouse oocytes by inducing sustained oscillations in cell $\mathrm{Ca}^{2+}$. Nature 316 541-542.

Cuthbertson KS, Whittingham DG \& Cobbold PH 1981 Free calcium increases in exponential phases during mouse oocyte activation. Nature 294 754-757.

Du ZF \& Wales RG 1993 Some effects of genotype and composition of the culture medium on the development of mouse zygotes in vitro. Reproduction, Fertility and Development 5 405-415.

Ducibella T, Huneau D, Angelichio E, Xu Z, Schultz RM, Kopf GS, Fissore R, Madoux S \& Ozil JP 2002 Egg-to-embryo transition is driven by differential responses to $\mathrm{Ca}^{2+}$ oscillation number. Developmental Biology 250 280-291.
Gao S, Czirr E, Chung YG, Han Z \& Latham KE 2004 Genetic variation in oocyte phenotype revealed through parthenogenesis and cloning: correlation with differences in pronuclear epigenetic modification. Biology of Reproduction $701162-1170$.

Goldbard SB \& Warner CM 1982 Genes affect the timing of early mouse embryo development. Biology of Reproduction 27 419-424.

He CL, Damiani P, Parys JB \& Fissore RA 1997 Calcium, calcium release receptors, and meiotic resumption in bovine oocytes. Biology of Reproduction 57 1245-1255.

Herman B, Langevin MA \& Albertini DF 1983 The effects of taxol in the organization of the cytoskeleton in cultured ovarian granulose cells. European Journal of Cell Biology 31 34-45.

Ibáñez E, Albertini DF \& Overström EW 2003 Demecolcine-induced oocyte enucleation for somatic cell cloning: coordination between cell-cycle egress, kinetics of cortical cytoskeletal interactions, and second polar body extrusion. Biology of Reproduction 68 $1249-1258$.

Ilyin V \& Parker I 1992 Effects of alcohols on responses evoked by inositol trisphosphate in Xenopus oocytes. Journal of Physiology $448339-354$

Kishikawa H, Wakayama T \& Yanagimachi R 1999 Comparison of oocyte-activating agents for mouse cloning. Cloning 3 153-159.

Kline D \& Kline JT 1992 Repetitive calcium transients and the role of calcium in exocytosis and cell cycle activation in the mouse egg. Developmental Biology 149 80-89.

Krivokharchenko A, Popova E, Zaitseva I, Vil'ianovich L, Ganten D \& Bader M 2003 Development of parthenogenetic rat embryos. Biology of Reproduction 68 829-836.

Kubiak JZ 1989 Mouse oocytes gradually develop the capacity for activation during the metaphase II arrest. Developmental Biology $136537-545$.

Kubiak JZ, Weber M, de Pennart H, Winston NJ \& Maro B 1993 The metaphase II arrest in mouse oocytes is controlled through microtubule-dependent destruction of cyclin B in the presence of CSF. EMBO Journal 12 3773-3778.

Latham KE 1994 Strain-specific differences in mouse oocytes and their contributions to epigenetic inheritance. Development 120 $3419-3426$.

Latham KE \& Solter D 1991 Effect of egg composition on the developmental capacity of androgenetic mouse embryos. Development $113561-568$

Latham KE \& Sapienza C 1998 Localization of genes encoding egg modifiers of paternal genome function to mouse chromosomes one and two. Development 125 929-935.

Liu L, Trimarchi JR, Oldenbourg R \& Keefe DL 2000 Increased birefringence in the meiotic spindle provides a new marker for the onset of activation in living oocytes. Biology of Reproduction 63 $251-258$.

Macháty Z \& Prather RS 1998 Strategies for activating nuclear transfer oocytes. Reproduction, Fertility and Development 10 599-613.

Marcus GJ 1990 Activation of cumulus-free mouse oocytes. Molecular Reproduction and Development 26 159-162.

Maro B, Johnson MH, Pickering SJ \& Flach G 1984 Changes in actin distribution during fertilization of the mouse egg. Journal of Embryology and Experimental Morphology 81 211-237.

Masui Y 1991 The role of cytostatic factor (CSF) in the control of oocyte cell cycle - a summary of 20 years of study. Development, Growth and Differentiation 33 543-551.

Mehlmann LM, Mikoshiba K \& Kline D 1996 Redistribution and increase in cortical inositol 1,4,5-trisphosphate receptors after meiotic maturation of the mouse oocyte. Developmental Biology $180489-498$.

Messinger SM \& Albertini DF 1991 Centrosome and microtubule dynamics during meiotic progression in the mouse oocyte. Journal of Cell Science 100 289-298.

Miyazaki S, Shirakaw H, Nakada K \& Honda Y 1993 Essential role of the inositol 1,4,5-trisphosphate receptors/ $/ \mathrm{Ca}^{2+}$ oscillations at fertilization of mammalian eggs. Developmental Biology 158 62-78. 
Moos J, Visconti P, Moore GD, Schultz R \& Kopf G 1995 Potential role of mitogen-activated protein kinase in pronuclear envelope assembly and disassembly following fertilisation of mouse eggs. Biology of Reproduction 53 692-699.

Nurse P 1990 Universal control mechanism regulating onset of M-phase. Nature 344 503-508.

O'Neill GT, Rolfe LR \& Kaufman MH 1991 Developmental potential and chromosome constitution of strontium-induced mouse parthenogenones. Molecular Reproduction and Development 30 214-219.

Ozil JP 1990 The parthenogenetic development of rabbit oocytes after repetitive pulsatile electrical stimulation. Development 109 $117-127$.

Ozil JP 1998 Role of calcium oscillations in mammalian egg activation: experimental approach. Biophysical Chemistry 72 141-152.

Polanski Z 1997a Genetic background of the differences in timing of meiotic maturation in mouse oocytes: a study using recombinant inbred strains. Journal of Reproduction and Fertility 109 109-114.

Polanski Z 1997b Strain differences in the timing of meiosis resumption in mouse oocytes: involvement of a cytoplasmic factor(s) acting presumably upstream of the dephosphorylation of p34cdc2 kinase. Zygote 5 105-109.

Presicce GA \& Yang X 1994 Nuclear dynamics of parthenogenesis of bovine oocytes matured in vitro for 20 and 40 hours and activated with combined ethanol and cycloheximide treatment. Molecular Reproduction and Development 37 61-68.

Roemer I, Reik W, Dean W \& Kloase J 1997 Epigenetic inheritance in the mouse. Current Biology 7 277-280.

Rybouchkin A, Dozortsev D, de Sutter PD \& Dhont M 1996 Factors affecting the role of the spindle during early response of mouse oocytes to ethanol stimulation. Journal of Experimental Zoology $275469-475$.

Schultz RM \& Kopf GS 1995 Molecular basis of mammalian egg activation. Current Topics in Developmental Biology 30 21-62.

Scott L \& Whittingham DG 1996 Influence of genetic background and media components on the development of mouse embryos in vitro. Molecular Reproduction and Development 43 336-346.

Soloy E, Kanka J, Viuff D, Smith SD, Callesesn H \& Greve T 1997 Time course of pronuclear deoxyribonucleic acid synthesis in parthenogenetically activated bovine oocytes. Biology of Reproduction $5727-35$.

Swann K 1990 A cytoplasmic sperm factor stimulates repetitive calcium increases and mimics fertilisation in hamster eggs. Development 110 1295-1302.

Swann K \& Ozil JP 1994 Dynamics of the calcium signal that triggers mammalian egg activation. International Review of Cytology $\mathbf{1 5 2}$ 183-222.

Vincent C, Cheek TR \& Johnson MH 1992 Cell cycle progression of parthenogenetically activated mouse oocytes to interphase is dependent on the level of internal calcium. Journal of Cell Science 103 389-396.

Wakayama T, Perry ACF, Zuccotti $M$, Johnson KR \& Yanagimachi $R$ 1998 Full-term development of mice from enucleated oocytes injected with cumulus cell nuclei. Nature 394 369-374.

Warner CM, Gollnick SO \& Goldbard SB 1987 Linkage of the preimplanation-embryo-development (Ped) gene to the mouse major histocompatibility complex (MHC). Biology of Reproduction 36 606-610.

Wickramasinghe D \& Albertini DF 1992 Centrosome phosphorylation and the developmental expression of meiotic competence in mouse oocytes. Developmental Biology 152 62-74.

Winston NJ \& Maro B 1995 Calmodulin-dependent protein kinase II is activated transiently in ethanol-stimulated mouse oocytes. Developmental Biology 170 350-352.

Zernicka-Goetz M, Ciemerych MA, Kubiak JZ, Tarkowski AK \& Maro B 1995 Cytostatic factor inactivation is induced by a calcium-dependent mechanism present until the second cell cycle in fertilized but not in parthenogenetically activated mouse eggs. Journal of Cell Science 198 469-474.

Received 5 August 2004

First decision 7 September 2004

Revised manuscript received 23 September 2004

Accepted 27 September 2004 